\title{
Caerulomycin A-An Antifungal Compound Isolated from Marine Actinomycetes
}

\author{
Vaibhav Ambavane1, Pradipta Tokdar1, Rajashri Parab1, E. S. Sreekumar1, Girish Mahajan1, \\ Prabhu Dutt Mishra1, Lisette D'Souza ${ }^{2}$, Prafull Ranadive ${ }^{{ }^{*}}$ \\ ${ }^{1}$ Natural Products Department, Piramal Enterprises Limited, Mumbai, India \\ ${ }^{2}$ Bioorganic Chemistry Laboratory, CSIR-National Institute of Oceanography, Dona Paula, Goa, India \\ Email: prafull.ranadive@piramal.com
}

Received 18 March 2014; revised 20 April 2014; accepted 26 May 2014

Copyright (C) 2014 by authors and Scientific Research Publishing Inc.

This work is licensed under the Creative Commons Attribution International License (CC BY). http://creativecommons.org/licenses/by/4.0/

c) (i) Open Access

\section{Abstract}

Actinomycetes have been prolific sources of novel secondary metabolites with a range of biological activities that may ultimately find application as therapeutic compounds. Hence several drug discovery companies are engaged in isolation of novel bioactive metabolites from these microbial sources. Antibiotics form the major class of such bioactive metabolites and have been widely used for treating infectious diseases. One of the most critical problems in clinical practice is the increase of prevalence of drug resistant strains, especially azole resistance among fungi. Due to this, there is a constant need for development of new antifungal antibiotics having novel scaffolds and/or mechanism of action. In our in-house screening program in the quest of novel and superior antifungal compounds, an actinomycetes strain PM0525875 was isolated from a marine invertebrate. The extracts of this microbe showed potent in-vitro antifungal activity against drug resistant fungal strains. The antifungal active peak from the extract obtained by shake flask fermentation was identified by chromatographic and other analytical techniques during bioactivity guided isolation. Later the fermentation conditions were optimized in $30 \mathrm{~L}$ fermentor for the production of sufficient amount antifungal compound for complete structural characterization. Consequently the fermented broth extract was subjected to bioactivity-guided fractionation, to isolate the active principle using different preparative chromatographic techniques followed by its characterization. The active principle was characterized to be Caerulomycin A. Minimum inhibitory concentration (MIC) of the compound was found in the range of $0.39-1.56 \mu \mathrm{g} / \mathrm{ml}$ against pathogenic fungal test strains. The phylogenetic analysis of producer strain using 16S rRNA sequence showed closest match with Actinoalloateichus cyanogriseus. Herewith we report the isolation of Caerulomycin A from marine invertebrate-associated Actinoalloteichus sp. using optimized medium and fermentation conditions.

\footnotetext{
${ }^{*}$ Corresponding author.
} 


\section{Keywords}

\section{Caerulomycin A, Antifungal, Non-Polyene, Actinoalloateichus cyanogriseus, Marine Actinomycetes}

\section{Introduction}

The incidences of invasive fungal infection are increasing due to number of immune compromised host and occurrence of antibiotic resistant strains [1]-[3]. The number of antifungal agent available for the treatment is limited and their use has been restricted because of toxicity or unfavorable pharmacokinetics profile. Hence, research interest has focused on discovery of safe and potent antifungal agent. One of the most successful approaches is to screen microbial resources to extract novel antifungal antibiotics.

Drug discovery from natural products has been traditionally focused on empirical exploitation of the most prolific microbial groups: actinomycetes and filamentous fungi. The literature vividly displays that actinomycetes have been the origin of the largest number of new antibiotic drug candidates and also lead molecules with applications in many other therapeutic areas [4] [5]. Access to the microbial diversity of actinomycetes in the environment has traditionally been focused on intensive sampling from a wide diversity of geographical locations and habitats [6]. One of the approaches is to explore untapped actinomycetes communities that might be associated with rhizospheres, plant endophytes, lichens, and entophytic bacteria [7] [8], as well as marine sediments and marine invertebrate-associated actinomycetes, which might facilitate isolation of novel microbial communities potentially producing novel chemical scaffolds [6].

Oceans, making up $70.8 \%$ of the surface of planet earth, contain untapped actinobacterial resources of bioactive compounds [9]. The salinity, low temperature, pressure and stress conditions in marine environments provoke a set of different metabolic pathways and defense system compared to their terrestrial counterparts, ensuring the potential ability to produce novel antibiotics [10]. According to recent findings, actinobacteria are widely distributed on the surface and inside animals and plants, in seawater and marine sediments. Marine-derived actinomycetes are rich sources of novel secondary metabolites having diverse bioactivity such as antimicrobial, antitumor and immunosuppressive [11]-[13]. The novel structure, promising biological properties and prospects of fermentation-based mass production have led to the renewed interest in the search for potential drug from marine microorganism.

During the ongoing screening program for the discovery of novel and superior antifungal compounds, an actinomycetes strain PM0525875 was isolated from a marine invertebrate. It showed potent in-vitro antifungal activity encompassing resistant fungal strains. The present work deals with the isolation and characterization of antifungal compound, Caerulomycin A from a marine-derived actinomycetes species.

\section{Materials and Methods}

\subsection{Isolation of Marine Actinomycetes}

Marine invertebrate sample (Sample ID: NIO_SA_An_15) was collected from deep sea (Anjuna Beach, Goa, India) in sterile polypropylene bag and stored at $4^{\circ} \mathrm{C}$. The invertebrate $(\sim 10 \mathrm{~g})$ sample was washed thrice with sterile demineralized water to remove the adhering particles like sand, sea weeds and then crushed in the sterile mortar and pestle. The crushed sample was serially diluted to $10^{-8}$. Last three dilutions viz. $10^{-6}, 10^{-7}$ and $10^{-8}$ were surface spreaded on the actinomycetes isolation agar (AIA) medium (Himedia, India) prepared in $75 \%(\mathrm{v} / \mathrm{v})$ artificial sea water (AS-AIA). The plates were incubated at $30^{\circ} \mathrm{C}$ till 30 days and observed periodically for the growth of actinomycetes colonies. The well isolated colonies were picked up, purified and grown on AS-AIA slants (made in $75 \%$ ASW). The well grown isolates on the slants were preserved at $4^{\circ} \mathrm{C}$.

\subsection{Primary Screening of Marine Actinomycetes for Antimicrobial Activity}

The isolated marine actinomycetes were screened for their antimicrobial activity. The loopful of the growth from the slant was inoculated into $50 \mathrm{ml}$ of seed medium; ASW-274(1) [glucose $15 \mathrm{~g} / \mathrm{L}$, corn steep liquor $5 \mathrm{~g} / \mathrm{L}$, sodium chloride $5 \mathrm{~g} / \mathrm{L}$, calcium carbonate $2 \mathrm{~g} / \mathrm{L}$, peptone $7.5 \mathrm{~g} / \mathrm{L}$, yeast extract $7.5 \mathrm{~g} / \mathrm{L}$, made in $75 \% \mathrm{ASW}$, pH 7.0 to 7.5] distributed in $250 \mathrm{ml}$ Erlenmeyer flask and incubated for $96 \mathrm{~h}$ at $30^{\circ} \mathrm{C}$ at $200 \mathrm{rpm}$ on a rotary shaker. 
A $3 \mathrm{ml}$ of well grown pure seed was transferred to the $100 \mathrm{ml}$ of each media in $500 \mathrm{ml}$ Erlenmeyer flask. Three different production media used were as followed: ASW-SM12(1) [glucose $50 \mathrm{~g} / \mathrm{L}$, yeast extract $11 \mathrm{~g} / \mathrm{L}$, peptone $4 \mathrm{~g} / \mathrm{L}$ beef extract $4 \mathrm{~g} / \mathrm{L}$, sodium chloride $2.5 \mathrm{~g} / \mathrm{L}$, calcium carbonate $5 \mathrm{~g} / \mathrm{L}$, made in $75 \% \mathrm{ASW}$, $\mathrm{pH} 7.4$ 7.6]; ASW-36P(1) [soluble starch $20 \mathrm{~g} / \mathrm{L}$, glucose $15 \mathrm{~g} / \mathrm{L}$, yeast extract $2 \mathrm{~g} / \mathrm{L}$, peptone $3 \mathrm{~g} / \mathrm{L}$, calcium carbonate $2 \mathrm{~g} / \mathrm{L}$, ammonium sulphate $0.5 \mathrm{~g} / \mathrm{L}$, corn steep liquor $2 \mathrm{~g} / \mathrm{L}$, sodium chloride $2 \mathrm{~g} / \mathrm{L}$, magnesium phosphate $5 \mathrm{~g} / \mathrm{L}$, cobalt chloride $0.001 \mathrm{~g} / \mathrm{L}$ and TSS $1 \mathrm{ml} / \mathrm{L}$ (copper sulphate $7 \mathrm{~g}$, ferrous sulphate $1 \mathrm{~g}$, manganese chloride $8 \mathrm{~g}$, zinc sulphate $2 \mathrm{~g}$ and demineralized water $1 \mathrm{~L}$ ), made in 75\% ASW pH 7.3 - 7.6]; ASW-1M [glycerol $30 \mathrm{~g} / \mathrm{L}$, glucose $3 \mathrm{~g} / \mathrm{L}$, yeast extract $2 \mathrm{~g} / \mathrm{L}$, sodium chloride $3 \mathrm{~g} / \mathrm{L}$, sodium nitrate $1 \mathrm{~g} / \mathrm{L}$, calcium carbonate $3 \mathrm{~g} / \mathrm{L}$, peptone $3 \mathrm{~g} / \mathrm{L}$ and TSS $1 \mathrm{ml} / \mathrm{L}$, made in 75\% ASW, pH 7.0 - 7.2]. The flasks were incubated for $96 \mathrm{~h}$ at $30^{\circ} \mathrm{C}$ on rotary shaker at $200 \mathrm{rpm}$. The $1 \mathrm{ml}$ of harvested whole broth was extracted with equal amount of methanol and centrifuged at $4000 \mathrm{rpm}$ for $10 \mathrm{~min}$. The supernatant was tested for antimicrobial activity by agar well diffusion method using different pathogenic strains [14]. LR grade chemicals were used in the study.

\subsection{Secondary Screening of Active Isolate and Antifungal Activity}

The isolate PM0525875 which exhibited exclusive antifungal activity was screened for its reproducibility as per the procedure mentioned in 2.2. The methanolic extract of the whole culture broth, cell mass extract and cell free culture filtrate were tested against Candida sp. to confirm the antifungal activity. To rule out the presence of polyene in the active extract, the UV-visible spectrum of extract was compared with the UV-visible spectrum of standard polyenes classes from the literature [15].

\subsection{Selection of Natural Variant and Screening in Shake Flask}

The $5 \mathrm{ml}$ of sterile tween $80(0.1 \%)$ was added to fully sporulated slant. The spores were scraped with sterile cell scraper. The spore suspension was filtered through sterile cotton to remove the mycelial residues. The spore suspension was spread on AS-AIA. The plates were incubated at $30^{\circ} \mathrm{C}$ for 30 days. The colonies having different morphology and sporulation pattern were picked up and transferred on AS-AIA slants. These variants were screened in shake flask as mentioned in 2.3. The harvested broth was extracted with equal amount of methanol and then serially diluted up to 1:1024 dilutions. Antifungal activities of this extract were checked by agar well diffusion assay [14].

\subsection{Phylogenetic Identification of PM0525875}

DNA was isolated from the active strain (PM0525875) grown in ASW-ISP2 (International Streptomyces Project Medium 2) containing [dextrose $4 \mathrm{~g} / \mathrm{L}$, yeast extract $4 \mathrm{~g} / \mathrm{L}$, malt extract $10 \mathrm{~g} / \mathrm{L}$, made in $75 \% \mathrm{ASW}, \mathrm{pH} 7.0$ to 7.5]. DNA from washed cell suspension was extracted using Ultraclean TM Tissue and Cells DNA Isolation kit, Mo Bio Laboratories, Inc. PCR-mediated amplification of 16S rRNA gene was carried out using 16 S universal primers: 8 F (AGAGTTTGATCCTGGCTCAG), 1492 R (ACGGCTACCTTGTTACGACTT) and BDTv3.1 Cycle sequencing kit on ABI 3730x1 Genetic Analyzer. The near complete 16S rRNA sequence (1377 bp) was desired and aligned with corresponding first ten matching sequences. The program CLUSTALW2

(www.ebi.ac.uk/Tools/msa/clustalw2/) was used for both multiple alignment and phylogenetic analyses. Based on maximum identity score, first ten sequences were selected and aligned using multiple alignment software program Clustal W. Distance matrix was generated using RDP database and phylogenic tree was constructed using MEGA5.

\subsection{Large Scale Fermentation}

The higher yielding variant (PM0525875-V4) was selected for cultivation in $30 \mathrm{~L}$ fermenter. The seed was prepared from 96 h grown culture in $200 \mathrm{ml} \mathrm{ASW-274(1)} \mathrm{medium} \mathrm{in} 1000 \mathrm{ml}$ Erlenmeyer flask. The fermenter was sterilized in-situ at $121^{\circ} \mathrm{C}$ for 25 min along with the ASW-36P(1) medium containing $0.04 \%$ antifoam. A 3\% of mature seed was aseptically inoculated into a fermenter. The fermentation process was carried out at $30^{\circ} \mathrm{C}, 180$ rpm, and $0.6 \mathrm{vvm}$ with a backpressure 0.5 bar and for $96 \mathrm{~h}$. Periodically $200 \mathrm{ml}$ of sample was aseptically withdrawn for determination of packed cell volume (PCV) and total sugar content [16]. The antifungal activity of extract was performed as mentioned in 2.4. 


\subsection{Bioactivity Guided Isolation and Purification}

The $8.5 \mathrm{~L}$ fermented broth was centrifuged at $4000 \mathrm{rpm}$ for $30 \mathrm{~min}$ to separate the biomass. The $400 \mathrm{~g}$ of biomass was extracted with methanol and clear solvent layer was obtained by filtration. Three subsequent extractions were performed. The extracts were pooled and concentrated to make it solvent free. The dried crude extract was suspended in demineralized water and further passed through a glass column packed with diaion HP-20 resin having bed volume $225 \mathrm{ml}$. The resin was washed twice with $3 \mathrm{~L}$ of demineralized water to remove the unbounded components and media particles. The resin column was further eluted with water and methanol gradient with varying polarity. The bioactive fractions were pooled together and evaporated till dryness with a rotary evaporator. The methanolic extract was further fractionated with petroleum ether followed by dichloromethane. The active dichloromethane extract (500 mg) was subjected to silica gel column chromatography and eluted with gradient of chloroform-methanol. The fractions were tested for bioactivity against Candida sp. (disc diffusion assay). The active fractions were pooled together and concentrated till dryness to get semi pure sample. The semi-pure material $(100 \mathrm{mg})$ was further purified by preparative chromatography using the following conditions: C-18 Eurospher column $(20 \mathrm{~mm} \times 250 \mathrm{~mm}, 10 \mu \mathrm{m})$ in isocratic mode and eluted with acetonitrile and $0.01 \mathrm{M}$ phosphate buffer (35:65) at a flow rate $20 \mathrm{ml} / \mathrm{min}$ with UV detection wave length at $220 \mathrm{~nm}$. The pure active fraction (eluted at 11 - $13 \mathrm{~min}$ ) was evaporated under reduced pressure and desalted using HP-20 resin followed by elution with methanol. The eluted solvent was concentrated to get pure compound $(20 \mathrm{mg})$. The purified compound was characterized by ${ }^{1} \mathrm{H}$ NMR, MS and IR spectroscopy. All the solvents used for extraction were of LR grade, where as HPLC grade solvents were used for analytical and preparative HPLC. Analytical HPLC purity was determined in Water's Empower software LC using Kromasil RP-18, SN: 39673 (150 mm × $4.6 \mathrm{~mm}$ ), $3.5 \mu \mathrm{m}$ column. Normal column chromatography (CC) was performed on Silica gel (60 - 120 \#) and TLC on Silica Gel $60 \mathrm{~F}_{254}(20 \times 20 \mathrm{~cm})$ aluminum sheets from Merck. NMR Spectra were recorded in DMSO-d6 on Bruker $300 \mathrm{MHz}$. Chemical shifts are expressed in ppm and tetramethylsilane was used as an internal standard. Mass spectra were taken on Bruker Daltonics system. IR spectra were recorded in pressed $\mathrm{KBr}$ discs with Perkin Elmer PARAGON1000 spectrometer.

\subsection{Determination of MIC of Isolated Bioactive Compound}

The MIC was determined by the NCCLS (CLSI) Macrobroth dilution method [17] [18]. The cultures used for the assay were Candida albicans, Candida albicans CO9, Candida glabrata ${ }^{\text {FlucR }} \mathrm{HO} 5$ and Candida krusei ${ }^{\text {FlucR }}$ GO3. The inoculum was prepared in sterile saline adjusted at an optical density (OD) of 1.00 at $600 \mathrm{~nm}$ comprising of $10^{8} \mathrm{cfu} / \mathrm{ml}$. The final working inoculum was $0.5 \times 10^{4} \mathrm{cfu} / \mathrm{ml}$. The bioactive compound was diluted in the concentration range of $0.019-10 \mu \mathrm{g} / \mathrm{ml}$. The concentration range for amphotericin B used was $0.031-16$ $\mu \mathrm{g} / \mathrm{ml}$ and for fluconazole was $0.5-256 \mu \mathrm{g} / \mathrm{ml}$. The assay tubes were incubated at $37^{\circ} \mathrm{C}$ for $48 \mathrm{~h}$ following which the visible growth was noted and the MIC value determined.

\section{Results}

\subsection{Isolation and Screening of Marine Actinomycetes}

Few actinomycetes colonies isolated from marine invertebrate sample (Sample ID: NIO_SA_An_15) were found to grow on ASW-AIA plate. The white sporulating slow growing colony showing black diffusible pigment on the agar was picked up and referred to as PM0525875. The extracts of PM0525875 showed exclusive antifungal activity, specific towards Candida albicans in Table 1. The medium ASW-36P(1) supported better activity than other two media. During the secondary screening, the antifungal activity against Candida albicans was determined and results are shown in Table 2. The culture filtrate obtained from all the three media did not show any active zone. The antifungal activity was found to be confined to mycelia, indicating its intracellular concentration. The medium ASW-36P(1) was shortlisted for large scale cultivation in fermenter. Based on the UV profile displayed the extract we ruled out presence of any polyene type of compound in it. Prior to it, total four of the morphological variants were selected (shown in Figure 1) and their antifungal activity was compared with the parent strain and results are showed in Table 3. The variant 4 (PM0525875-V4) displayed best antifungal activity as it showed the antifungal activity at the lowest dilution of broth (1:64). So PM0525875-V4 was selected for further studies. 


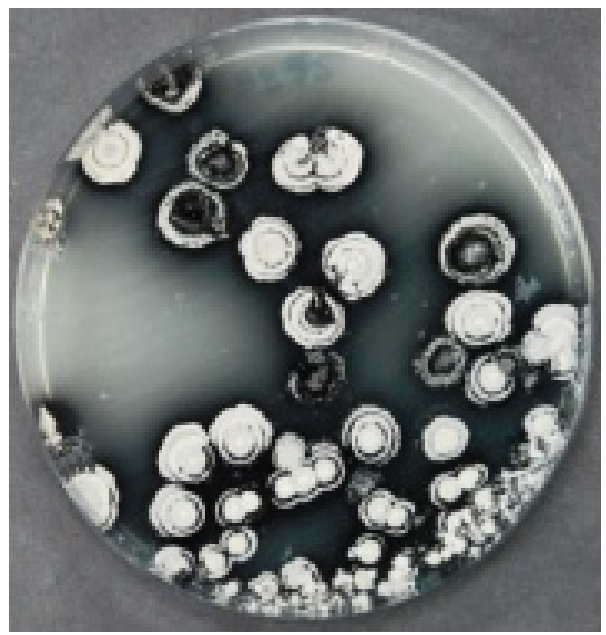

Figure 1. Natural variants of PM0525875 on ASW-AIA plate.

Table 1. Primary screening: antimicrobial activity of PM0525875 using agar well diffusion method.

\begin{tabular}{|c|c|c|c|c|c|c|c|}
\hline \multirow{3}{*}{ Seed medium } & \multirow{3}{*}{$\begin{array}{l}\text { Production } \\
\text { medium }\end{array}$} & \multicolumn{6}{|c|}{ Test cultures } \\
\hline & & $\begin{array}{c}\text { Aspergillus } \\
\text { fumigatus }\end{array}$ & $\begin{array}{l}\text { Candida } \\
\text { albicans }\end{array}$ & $\begin{array}{l}\text { Staphylococcus } \\
\text { aureus 209P }\end{array}$ & $\begin{array}{c}\text { Escherichia } \\
\text { coli ATCC } \\
25922\end{array}$ & $\begin{array}{c}\text { Escherichia } \\
\text { coli ATCC } \\
20732\end{array}$ & $\begin{array}{c}\text { Escherichia } \\
\text { coli ATCC } \\
35218\end{array}$ \\
\hline & & \multicolumn{6}{|c|}{ (Zone of inhibition in mm) } \\
\hline ASW-274(1) & ASW-SM12(1) & 8 & 9 & Nil & Nil & Nil & Nil \\
\hline ASW-274(1) & ASW-36P(1) & 8 & 14 & Nil & Nil & Nil & Nil \\
\hline ASW-274(1) & ASW-1M & Nil & 9 & Nil & Nil & Nil & Nil \\
\hline \multicolumn{8}{|c|}{ Standard antibiotics } \\
\hline \multicolumn{2}{|c|}{$\begin{array}{c}\text { Amphotericin B } \\
(20 \mu \mathrm{g} / \mathrm{ml})\end{array}$} & 18 & 20 & NA & NA & NA & NA \\
\hline \multicolumn{2}{|c|}{$\begin{array}{c}\text { Vancomycin } \\
(50 \mu \mathrm{g} / \mathrm{ml})\end{array}$} & NA & NA & 14 & NA & NA & NA \\
\hline \multicolumn{2}{|c|}{$\begin{array}{l}\text { Gentamicin } \\
(100 \mu \mathrm{g} / \mathrm{ml})\end{array}$} & NA & NA & NA & 14 & 14 & 15 \\
\hline
\end{tabular}

Nil—No zone of inhibition seen, NA—Not Applicable.

Table 2. Secondary screening of PM0525875: bioactivity of extracts against Candida albicans using agar well diffusion method.

\begin{tabular}{cccc}
\hline Seed medium & Production medium & Extraction method & $\begin{array}{c}\text { Zone of inhibition (mm) against } \\
\text { Candida albicans }\end{array}$ \\
\hline \multirow{2}{*}{ ASW-274(1) } & ASW-SM12(1) & Whole Broth Extract & 11 \\
& & Mycelial Extract & 10 \\
& & Culture Filtrate & Nil \\
ASW-274(1) & ASW-36P(1) & Whole Broth Extract & 12 \\
& & Mycelial Extract & Nil \\
& & Culture Filtrate & 9 \\
ASW-274(1) & ASW-1M & Whole Broth Extract & 9 \\
& & Mycelial Extract & Nil \\
\hline
\end{tabular}

Nil—No zone of inhibition seen. 
Table 3. Comparison between antifungal activity of original isolate PM0525875 and its variants (serial dilution of whole broth extract, by agar well diffusion assay).

\begin{tabular}{|c|c|c|c|c|c|}
\hline \multirow{2}{*}{ Dilution of broth } & Original isolate & Variant 1 & Variant 2 & Variant 3 & Variant 4 \\
\hline & \multicolumn{5}{|c|}{ Zone of inhibition in (mm) against Candida albicans } \\
\hline $1: 02$ & 11.9 & 13.1 & 13.1 & 10.6 & 14.7 \\
\hline 1:04 & 9.1 & 12.23 & 12.3 & 8.4 & 13.8 \\
\hline $1: 08$ & 7 & 10.8 & 11 & Nil & 11.1 \\
\hline $1: 16$ & Nil & 9.2 & 9.9 & Nil & 9.9 \\
\hline $1: 32$ & Nil & Nil & Nil & Nil & 8.7 \\
\hline $1: 64$ & Nil & Nil & Nil & Nil & Nil \\
\hline \multicolumn{2}{|c|}{ Amphotericin B $(20 \mu \mathrm{g} / \mathrm{ml})$} & 20 & 20 & 20 & 20 \\
\hline
\end{tabular}

Nil-No zone of inhibition seen.

\subsection{Large Scale Fermentation of PM0525875-V4}

Large scale fermentation was carried out using PM0525875-V4 and fermentation medium ASW-36P(1). The fermentation was carried out till $96 \mathrm{~h}$. The time course of fermentation batch is shown in Table 4 and expressed in graphical form as shown in Figure 2. During fermentation, the $\mathrm{pH}$ was dropped with the time and later maintained to 6.5 till end of the fermentation. The rise in biomass (PCV) was slow initially and was picked up after $24 \mathrm{~h}$. After $48 \mathrm{~h}$, the growth rate was steady and the stationary phase was achieved. Dissolve oxygen (DO) dropped significantly till $24 \mathrm{~h}$ and was maintained at around $40 \%$ till end of the process. The total sugar consumption was slow at beginning and it was reduced to half of the concentration at $48 \mathrm{~h}$. Based on the bioactivity pattern obtained by the broth dilution method (as mentioned in 2.4), the maximum activity was attended at $72 \mathrm{~h}$ and maintained steady till end of the fermentation process. Hence, the fermentation cycle was terminated at 96 h.

\subsection{Isolation and Characterization of Bioactive Compound}

The active compound was found to be intracellular, hence mycelial extract was subjected to bioactivity guided isolation and purification as mentioned in 2.7. The active compound was able to adsorb on HP-20 resins. Further fractionation of crude material using petroleum ether helped removing the impurities and subsequent dichloromethane fraction was found to be active. The pure compound was finally isolated by silica gel chromatography followed by preparative HPLC using RP-18 resin. The characterization of isolated compound was carried out based on data obtained from mass, IR and ${ }^{1} \mathrm{H}$ NMR spectra (Figures 3-5). In ${ }^{1} \mathrm{H}$ NMR spectra, the signals at $\delta$ 7.8 and 7.35 were assigned for protons attached at C-3 and C-5 respectively. Proton at unsaturated C-7 appeared at $\delta 8.13$ due to nitrogen and $\mathrm{OH}$ group being in proximity. The aromatic protons associated with other pyridine ring were assigned in the range of $\delta 7.4$ - 8.3. The O-methyl group showed a singlet for $3 \mathrm{H}$ at $\delta$ 3.9. Structural confirmation was done by comparing the spectral values with the published data [19]. Based on the data, the active compound was characterized as Caerulomycin A. Figure 6 and its chemical properties are shown in Table 5. From the final yield of the isolated compound $(20 \mathrm{mg}$ from $8.5 \mathrm{~L}$ broth), the back calculated titer in the harvested broth was estimated as $2.3 \mathrm{mg} / \mathrm{L}$. In order to simplify the extraction method for scale-up purification, the whole broth extraction with equal quantity of ethyl acetate was attempted. Caerulomycin A was found to be completely extractable in ethyl acetate hence this method could be used for large scale extraction batches.

\subsection{Phylogenetic Analysis of PM0525875}

The 16S rRNA gene from PM0525875 was sequenced. The partial sequence containing 1377 nucleotide base pairs showed close similarity with Actinoalloteichus cyanogriseus. The phylogenic tree constructed using ten matching sequences of 16S rRNA from NCBI data-base is shown in Figure 7. The evolutionary history was inferred using the Neighbor-Joining method [20]. The bootstrap consensus tree inferred from 500 replicates was represented in the evolutionary history of the taxa [21] and the branches corresponding to partitions reproduced in less than 50\% bootstrap replicates were collapsed. The evolutionary distances were computed using the Kimura 2-parameter method [22]. The analysis involved 11 nucleotide sequences and the codon positions included 


\section{$\mathrm{DO} \% \rightarrow \mathrm{PCV}(\%) \mp$ Total Sugar $(g / \mathrm{L})-\mathrm{pH}$}

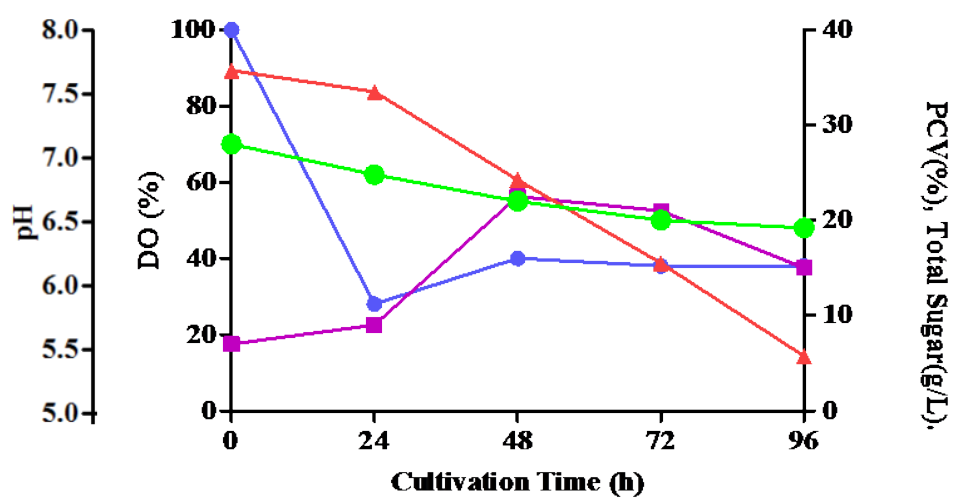

Figure 2. Time course of fermentation process showing $\mathrm{pH}$, packed cell volume (PCV), dissolved oxygen (DO), and total sugar consumed.

Table 4. Fermentor batch parameters.

\begin{tabular}{cccccc}
\hline Cultivation time (h) & pH & PCV (\%) & DO (\%) & $\begin{array}{c}\text { Total sugar } \\
\text { (g/L) }\end{array}$ & $\begin{array}{c}\text { Bioactivity against Candida albicans } \\
\text { (lowest dilution of broth showing } \\
\text { bioactive zones) }\end{array}$ \\
\hline 0 & 7.02 & 7 & 100 & 35.75 & NA \\
24 & 6.90 & 9 & 28 & 33.50 & NA \\
48 & 6.65 & 22.5 & 40 & 24.25 & $1: 16$ \\
72 & 6.55 & 21 & 38 & 15.50 & $1: 32$ \\
96 & 6.54 & 15 & 38 & 5.75 & $1: 32$ \\
\hline
\end{tabular}

*Agar well diffusion method, NA—Not Applicable.

Table 5. Physico-chemical and spectroscopic properties of isolated compound-Caerulomycin A.

\begin{tabular}{cc}
\hline Appearance & White powder \\
\hline Molecular weight & $230.23[\mathrm{M}+\mathrm{H}]^{+}, 252.19[\mathrm{M}+\mathrm{Na}]^{+}$ \\
IR (KBr) & $3498.09,3193.70,2848.56,1605.37$ 1573.50, 1588.91, 1430.68, $1360.77 \mathrm{~cm}^{-1}$ \\
& $\delta 7.8(\mathrm{H}-3), 7.35(\mathrm{H}-5), 8.13(\mathrm{H}-7), 8.3\left(\mathrm{H}-3^{\prime}\right), 7.9\left(\mathrm{H}-4^{\prime}\right), 7.4\left(\mathrm{H}-5^{\prime}\right), 8.6\left(\mathrm{H}^{\prime} 6^{\prime}\right)$, \\
& $3.93(4-\mathrm{OCH}), 11.69(\mathrm{OH})$ \\
\hline
\end{tabular}

were 1st + 2nd + 3rd + Noncoding. There were a total of 1381 positions in the final datasheet. Evolutionary analyses were conducted on computer software MEGA5 [23]. Based on this results the isolated actinomycetes strain was identified as Actinoalloteichus cyanogriseus. The gene sequence was deposited in NCBI GenBank under accession no KF861694.1.

\subsection{MIC of Caerulomycin A}

MIC of the isolated compound Caerulomycin A and two standard antifungal compounds was determined using NCCLS Macrobroth dilution method and results are shown in Table 6. Caerulomycin A showed potent activity against four Candida strains, including two fluconazole resistant strains. The MIC of the compound was in the range of $0.39-1.256 \mu \mathrm{g} / \mathrm{ml}$. The MIC values obtained of Caerulomycin A against fluconazole resistant Candida glabrata were comparable with the MIC values obtained for Amphotericin B. This result indicates the potential of Caerulomycin A as a potent and broad spectrum antifungal agent. 


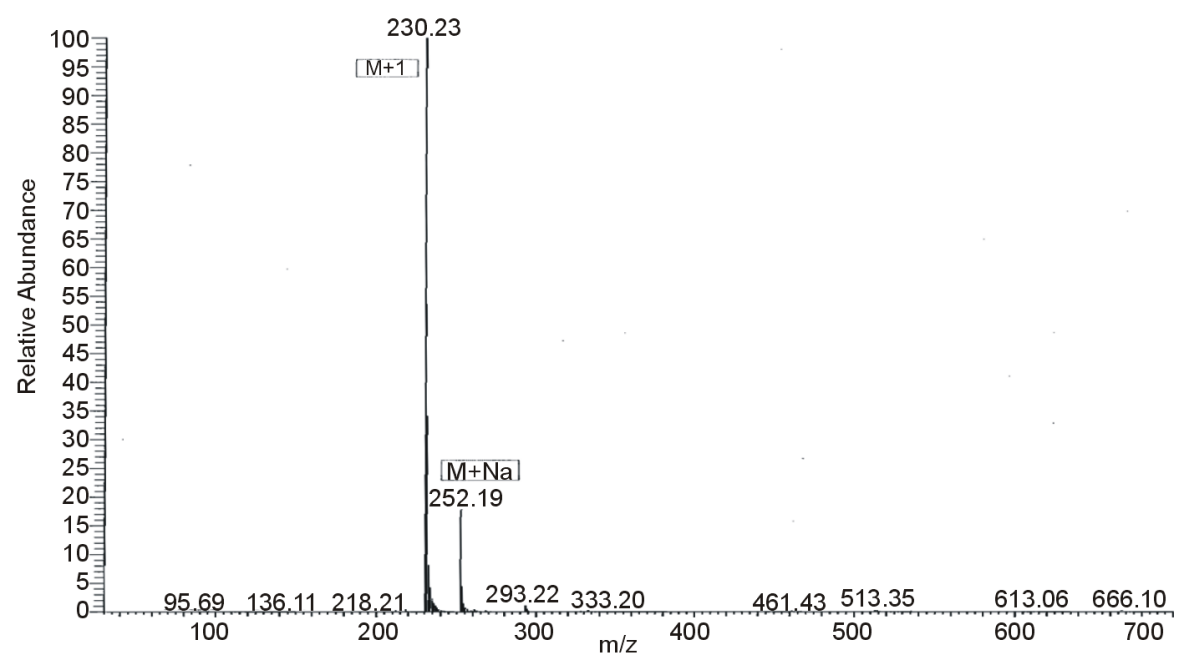

Figure 3. ESI-MS spectrum of Caerulomycin A.

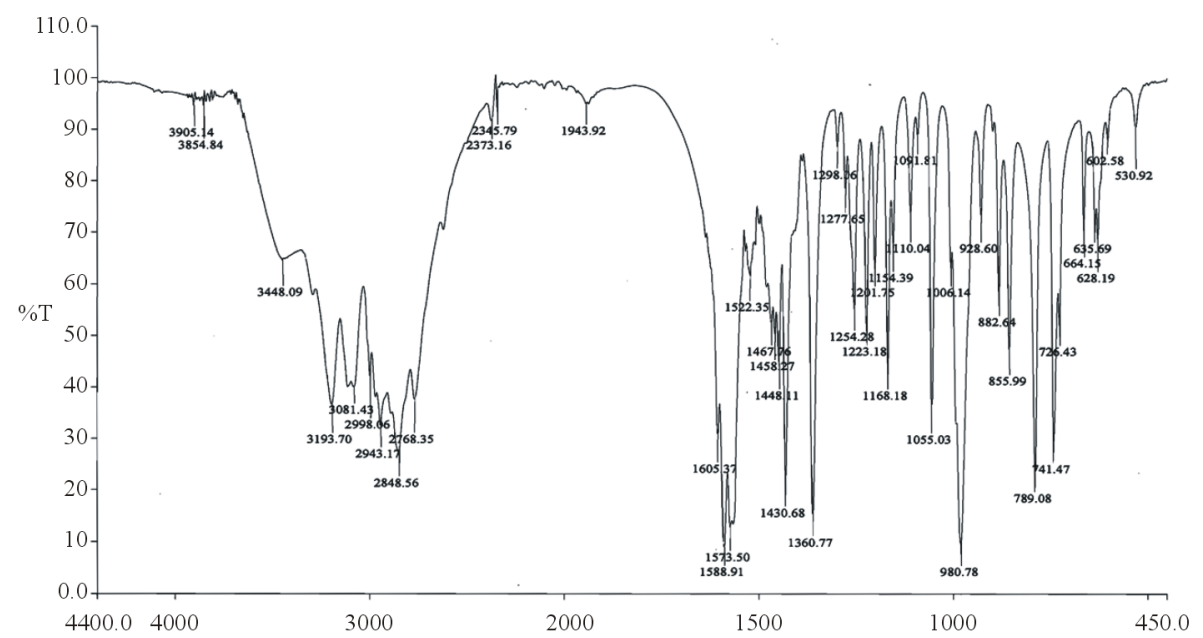

Figure 4. IR spectrum of Caerulomycin A.

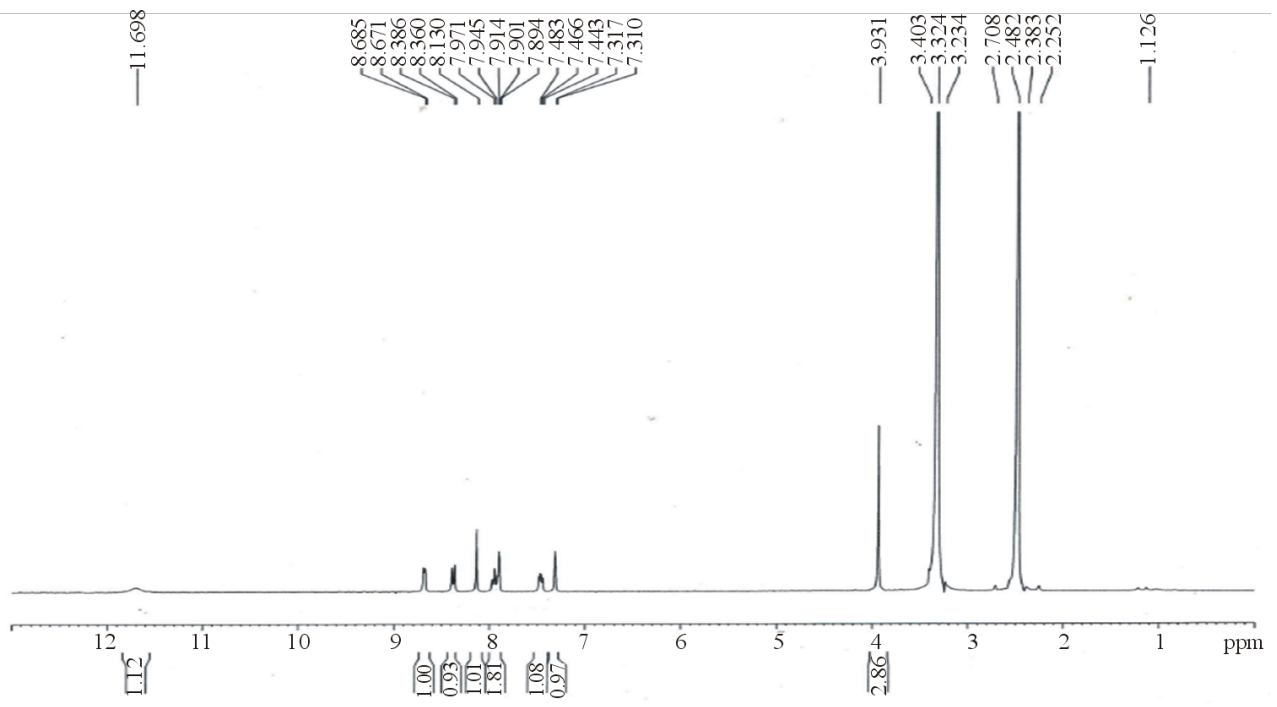

Figure 5. ${ }^{1} \mathrm{H}$ NMR spectrum of Caerulomycin A. 


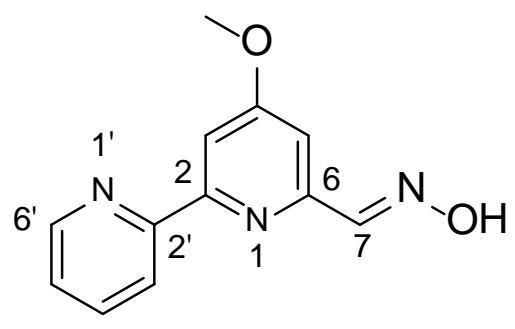

Figure 6. Structure of Caerulomycin A.

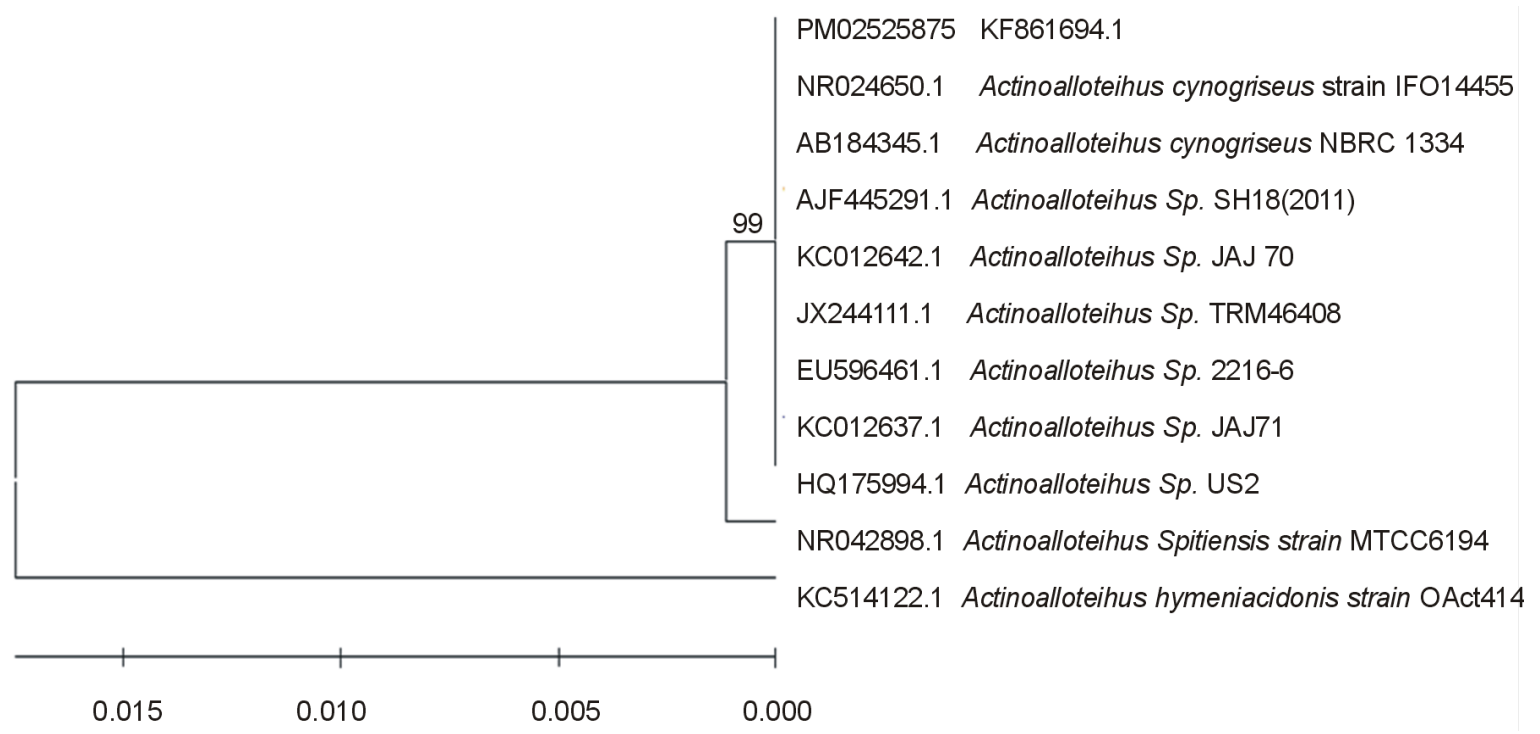

Figure 7. Phylogenic tree showing relationship between PM0525875 and Actinoalloteichus sp. based on clustering of the sequences of the 16S rRNA gene (coefficient of neighbour-joining) by using MEGA5 software.

Table 6. MIC of Caerulomycin A and standard antifungal compounds against selected fungal strains.

\begin{tabular}{ccccc}
\hline \multirow{2}{*}{ Sr. No } & \multirow{2}{*}{ Test Organism } & \multicolumn{3}{c}{ MIC $(\boldsymbol{\mu g} / \mathbf{m l})$} \\
\cline { 3 - 5 } & & Caerulomycin A & Amphotericin B & Fluconazole \\
\hline 1 & Candida albicans & $0.78-1.56$ & $0.39-0.78$ & $>256$ \\
2 & Candida albicans CO9 & $0.78-1.56$ & $0.195-0.39$ & NT \\
3 & Candida glabrata HO5 $^{\text {FlucR }}$ & $0.39-0.78$ & $0.313-0.625$ & $>256$ \\
4 & Candida krusei GO3 $^{\text {FlucR }}$ & $0.78-1.56$ & $0.313-0.625$ & 64 \\
\hline
\end{tabular}

NT: Not Tested.

\section{Discussion}

The global antifungal market was estimated at $\$ 9.4$ billion in 2010 and is expected to grow at a rate of $1.9 \%$ during 2010-2017. The major class of antifungal compound includes azoles, polyenes, pyrimidines, allyamines and echinodians. The antifungal therapies intend eradicating fungi through several action mechanisms, mainly involving destruction of cell wall and inhibition of cell division. There is a significant unmet need of novel antifungal compounds, because the present portfolio of treatments interact unfavorably with other medication, have resistance problem, low spectrum of activity, are fungistatic as opposed to fungicidal and are often toxic. Hence research has been focused on development of potent and safe antifungal compounds, either synthetic or from microbial sources [24]. In the present study, we exploited the marine resources for isolation of actinomycetes strains producing antifungal compounds. In the course of study, the marine invertebrate associated active actinomycetes strain PM0525875 was isolated and identified as Actinoalloteichus cyanogriseus. The antifungal principle from this strain was characterized as Caerulomycin A that showed potent in-vitro activity against pa- 
thogenic and drug resistant Candida strains.

Caerulomycin A was first isolated from S. caeruleus [25] [26] as an antibiotic. Later it was reported to have anti-cancer activity [27]. In-vitro and in-vivo activity of Caerulomycin A against Entamoeba histolytica has been reported [28]. Natural derivatives of Caerulomycin A has also been reported [29]. Caerulomycin B and C, a new 2,2'-dipyridyl derivatives were isolated from Streptomyces caeruleus supplemented with $1 \mathrm{mM}$ L-tryptophan. This group also reported the isolation of Caerulomycin D [19]. Additional natural derivatives of Caerulomycin F-K were isolated from marine derived actinomycetes (Actinoalloteichus cyanogriseus) that showed anticancer and antibacterial activity [29]. Lin et al. identified the biosynthetic gene cluster for Caerulomycin A from marine actinomycetes Actinoalloteichus cyanogriseus. It mainly consists of unusual hybrid polyketide synthase (PKS) and nonribosomal peptide synthetase (NRPS) [30]. The biosynthesis of Caerulomycin A based on enzymatic modifications leading to structural changes, have been studied [31]. Chemical synthesis of Caerulomycin A-C has also been reported [32] [33]. The immunosuppressive activity of Caerulomycin A and its natural analogues has been reported [34].

Although Caerulomycin A has not been entered in clinic so far, may be due to its limitations, it could be the ideal molecule for generating semi synthetic druggable derivatives having potential application as an anticancer, antifungal or immunosuppressive drug. The strain and the optimized fermentation process described here could be useful for large scale production of this molecule for further drug development studies.

\section{Conclusion}

In our in-house screening program in the quest of novel and superior antifungal compounds, an actinomycetes strain PM0525875 was isolated from a marine invertebrate. The active principle was characterized to be Caerulomycin A. Minimum inhibitory concentration (MIC) of the compound was found in the range of $0.39-1.56$ $\mu \mathrm{g} / \mathrm{ml}$ against pathogenic fungal test strains. The phylogenetic analysis of producer strain using $16 \mathrm{~S}$ rRNA sequence showed closest match with Actinoalloateichus cyanogriseus. Overall, Caerulomycin A was isolated from marine invertebrate-associated Actinoalloteichus sp. using optimized medium and fermentation conditions.

\section{Acknowledgements}

The authors are very grateful to Dr. Arun Balakrishnan, Senior Vice-President, Piramal Enterprises Limited, Mumbai, India for his continuous encouragement towards this project.

\section{References}

[1] Martin, G.S., Mannino, D.M., Eaton, S. and Moss, M. (2003) The Epidemiology of Sepsis in the United States from 1979 through 2000. New England Journal of Medicine, 348, 1546-1554. http://dx.doi.org/10.1056/NEJMoa022139

[2] Zilberberg, M.D., Shorr, A.F. and Kollef, M.H. (2008) Secular Trends in Candidemiarelated Hospitalization in the United States from 2000-2005. Infection Control and Hospital Epidemiology, 29, 978-980.

http://dx.doi.org/10.1086/591033

[3] Wisplinghoff, H., Bischoff, T., Tallent, S.M., Seifert, H., Wenzel, R.P. and Edmond, M.B. (2004) Nosocomial Bloodstream Infections in US Hospitals: Analysis of 24,179 Cases from a Prospective Nationwide Surveillance Study. Clinical Infectious Diseases, 39, 309-317. http://dx.doi.org/10.1086/421946

[4] Berdy, J. (2005) Bioactive Microbial Metabolites, a Personal View. Journal of Antibiotics, 58, 1-26. http://dx.doi.org/10.1038/ja.2005.1

[5] Singh, S.B. and Pelaez, F. (2010) Terrestrial Microorganisms: Filamentous Bacteria. In: Mander, L. and Liu, H.-W., Eds., Comprehensive Natural Products II, Elsevier, Amsterdam, 109-140. http://dx.doi.org/10.1016/B978-008045382-8.00036-8

[6] Genilloud, O., Gonzalez, I., Salazer, O., Martin, J., Tormo, J.R. and Vicente, F. (2011) Current Approaches to Exploit Actinomycetes as a Source of Novel Natural Products. Journal of Industrial Microbiology Biotechnology, 38, 375-389. http://dx.doi.org/10.1007/s10295-010-0882-7

[7] Gonzalez, I., Ayuso-Sacido, A., Anderson, A. and Genilloud, O. (2005) Actinomycetes Isolated from Lichens: Evaluation of Their Diversity and Detection of Biosynthetic Gene Sequences. FEMS Microbiology Ecology, 54, 401-415. http://dx.doi.org/10.1016/j.femsec.2005.05.004

[8] Salazar, O., Valverde, A. and Genilloud, O. (2006) Real-Time PCR for the Detection and Quantification of Geodermatophilaceae from Stone Samples and Identification of New Members of the Genus Blastococcus. Applied and Environmental Microbiology, 72, 346-352. http://dx.doi.org/10.1128/AEM.72.1.346-352.2006 
[9] Bull, A.T., Stach, J.E., Ward, A.C. and Goodfellow, M. (2005) Marine Actinobacteria: Perspectives, Challenges, Future Directions. Antonie Van Leeuwenhoek, 87, 65-79. http://dx.doi.org/10.1007/s10482-004-6562-8

[10] Lam, K.S. (2006) Discovery of Novel Metabolites from Marine Actinomycetes. Current Opinion in Microbiology, 9, 245-251. http://dx.doi.org/10.1016/j.mib.2006.03.004

[11] Manivasagan, P., Venkatesan, J., Sivakumar, K. and Kim, S.K. (2013) Marine Actinobacterial Metabolites: Current Status and Future Perspectives. Microbiological Research, 168, 311-332. http://dx.doi.org/10.1016/j.micres.2013.02.002

[12] Zotchev, S.B. (2011) Marine Actinomycetes as an Emerging Resource for the Drug Development Pipelines. Journal of Biotechnology, 158, 168-175. http://dx.doi.org/10.1016/j.jbiotec.2011.06.002

[13] Blunt, J.W., Copp, B.R., Keyzers, R.A., Munro, M.H.G. and Prinsep, M.R. (2013) Marine Natural Products. Natural Product Reports, 30, 237-323. http://dx.doi.org/10.1039/c2np20112g

[14] Hooper, J. and Parisot, J. (2008) Principles of Assessing Bacterial Susceptibility to Antibiotics Using the Agar Diffusion Method. Journal of Antimicrobial Chemotherapy, 61, 1295-1301. http://dx.doi.org/10.1093/jac/dkn090

[15] Ball, S., Bessell, C.J. and Mortimer, A. (1957) The Production of Polyenic Antibiotics by Soil Streptomycetes. Journal of General Microbiology, 17, 96-103. http://dx.doi.org/10.1099/00221287-17-1-96

[16] Trevelyan, W.E., Forrest, R.S. and Harrison, J.S. (1952) Determination of Yeast Carbohydrates with the Anthrone Reagent. Nature, 170, 626-627. http://dx.doi.org/10.1038/170626a0

[17] NCCLS (2002) Reference Method for Broth Dilution Antifungal Susceptibility Testing of Yeasts; Approved Standard-Second Edition. NCCLS Document M27-A2, Wayne, Pennsylvania.

[18] NCCLS (2002) Reference Method for Broth Dilution Antifungal Susceptibility Testing of Filamentous Fungi; Approved Standard-Second Edition. NCCLS Document M38-A, Wayne, Pennsylvania.

[19] McInnes, A.G., Smith, D.G., Wright, J.L.C. and Vining, L.C. (1977) Caerulomycin B and C, New 2,2'-Dipyridyl Derivatives from Streptomyces caeruleus. Canadian Journal of Chemistry, 55, 4159-4165. http://dx.doi.org/10.1139/v77-589

[20] Saitou, N. and Nei, M. (1987) The Neighbor-Joining Method: A New Method for Reconstructing Phylogenetic Trees. Molecular Biology and Evolution, 4, 406-425.

[21] Felsenstein, J. (1985) Confidence Limits on Phylogenies: An Approach Using the Bootstrap. Evolution, 39, $783-791$. http://dx.doi.org/10.2307/2408678

[22] Kimura, M. (1980) A Simple Method for Estimating Evolutionary Rate of Base Substitutions through Comparative Studies of Nucleotide Sequences. Journal of Molecular Evolution, 16, 111-120. http://dx.doi.org/10.1007/BF01731581

[23] Tamura, K., Peterson, D., Peterson, N., Stecher, G., Nei, M. and Kumar, S. (2011) MEGA5: Molecular Evolutionary Genetics Analysis Using Maximum Likelihood, Evolutionary Distance and Maximum Parsimony Methods. Molecular Biology and Evolution, 28, 2731-2739. http://dx.doi.org/10.1093/molbev/msr121

[24] Antifungals Market to 2017-Generic Erosion of Major Polyenes, Azoles, Allylamines and Echinocandins to Slow Value Growth (2012).

http://www.gbiresearch.com/Report.aspx?ID=Antifungals-Market-to-2017-Generic-Erosion-of-Major-Polyenes-Azoles -Allylamines-and-Echinocandins-to-Slow-Value-Growth\&ReportType=Industry_Report

[25] Funk, A. and Divekar, P.V. (1959) Caerulomycin, a New Antibiotic from Streptomyces caeruleus. I. Production, Isolation, Assay and Biological Properties. Canadian Journal of Microbiology, 5, 317-321. http://dx.doi.org/10.1139/m59-039

[26] Divekar, P.V., Read, G. and Vising, L.C. (1967) Caerulomycin, a New Antibiotic from Streptomycin caeruleus Baldacci. II Structure. Canadian Journal of Chemistry, 45, 1215-1223. http://dx.doi.org/10.1139/v67-201

[27] Vinothkumar, S. and Parameswaran, P.S. (2013) Recent Advances in Marine Drug Research. Biotechnology Advances, 31, 1826-1845. http://dx.doi.org/10.1016/j.biotechadv.2013.02.006

[28] Chatterjee, D.K., Raether, W., Iyer, N. and Ganguli, B.N. (1984) Caerulomycin, an Antifungal Antibiotic with Marked in Vitro and in Vivo Activity against Entamoeba histolytica. Zeitschrift fürm Parasitenkunde, 70, 569-573.

[29] Blunt, J.W., Copp, B.R., Keyzers, R.A., Munro, M.H.G. and Prinsep, M.R. (2013) Marine Natural Products. Natural Product Reports, 30, 237-323. http://dx.doi.org/10.1039/c2np20112g

[30] Lin, Q., Zhang, G., Li, S., Zhang, H., Ju, J., Zhu, W. and Zhang, C. (2011) Development of a Genetic Modification System for Caerulomycin Producer Actinoalloteichus sp. WH1-2216-6. Wei Sheng Wu Xue Bao, 51, 1032-1041.

[31] Zhu, Y., Zhang, Q., Li, S., Lin, Q., Fu, P., Zhang, G., Zhang, H., Shi, R., Zhu, W. and Zhang, C. (2013) Insights into Caerulomycin A Biosynthesis: A Two-Component Monooxygenase CrmH-Catalyzed Oxime Formation. Journal of the American Chemical Society, 135, 18750-15753. http://dx.doi.org/10.1021/ja410513g 
[32] Trecourt, F., Gervais, B., Mallet, M. and Queguiner, G. (1996) First Synthesis of Caerulomycin C. The Journal of Organic Chemistry, 61, 1673-1676. http://dx.doi.org/10.1021/jo950823k

[33] Ranganthan, S., Singh, B.B. and Divekar, P.V. (1968) Synthesis of Caerulomycin. Canadian Journal of Chemistry, 46, 165-166.

[34] Singla, A.K., Agrewala, J.N., Vohra, R.M. and Singh, J.R. (2007) Use of Bipyridine Compound Caerulomycin A Derivates and Analogs Thereof as Immunosuppressive Agents. US Patent WO2007031832A2. 
Scientific Research Publishing (SCIRP) is one of the largest Open Access journal publishers. It is currently publishing more than 200 open access, online, peer-reviewed journals covering a wide range of academic disciplines. SCIRP serves the worldwide academic communities and contributes to the progress and application of science with its publication.

Other selected journals from SCIRP are listed as below. Submit your manuscript to us via either submit@scirp.org or Online Submission Portal.
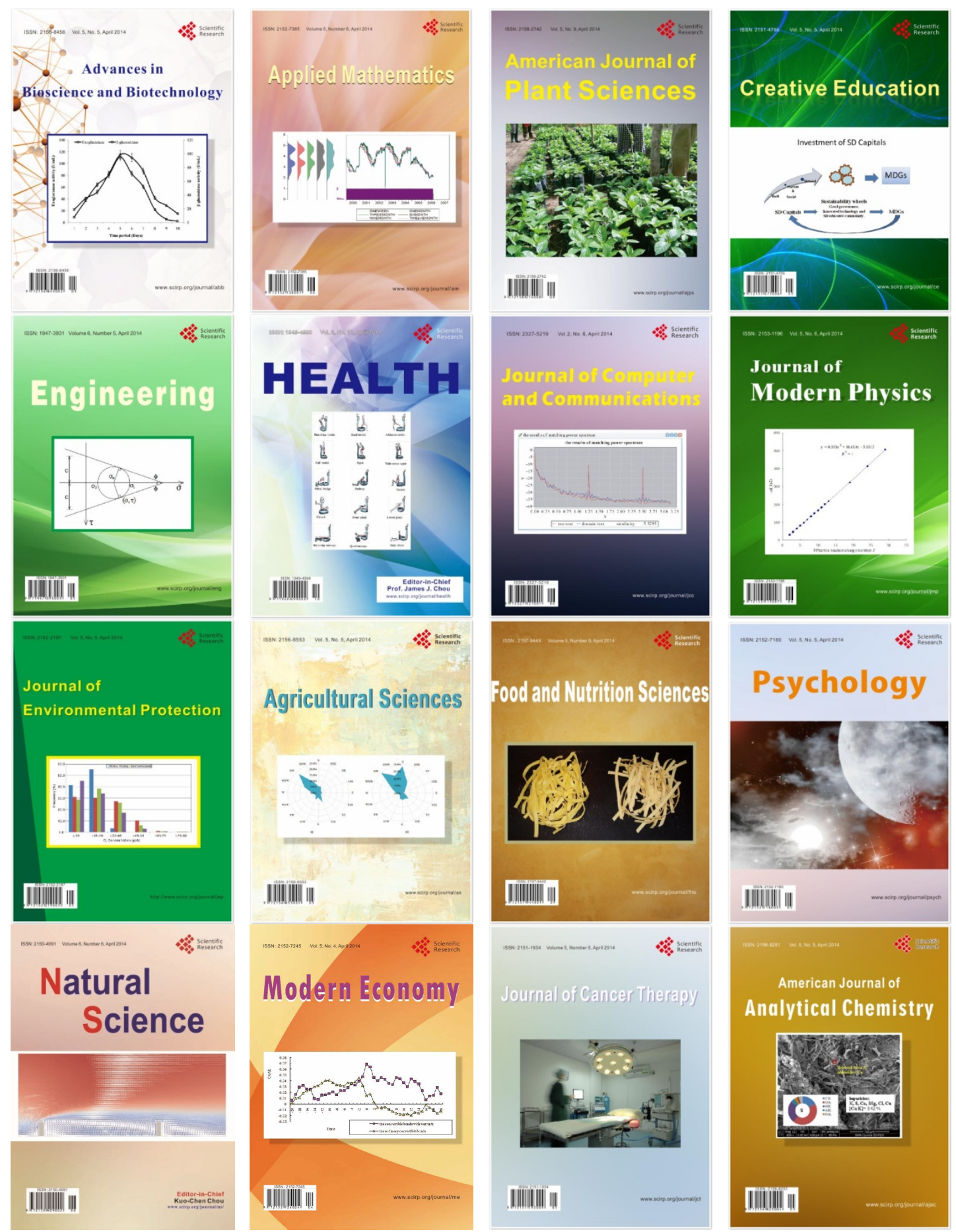